\title{
ALFABETIZAÇÃO E LETRAMENTO NA EJA SOB A ÓTICA DISCENTE: PROBLEMATIZANDO AS PRÁTICAS ESCOLARES
}

\author{
Irlanda do Socorro de Oliveira Miléo ${ }^{1}$ \\ Léia Gonçalves de Freitas ${ }^{2}$
}

\begin{abstract}
RESUMO
Esta pesquisa problematiza as possíveis dificuldades enfrentadas no percurso formativo dos alunos da Educação de Jovens e Adultos - EJA de uma escola pública no município de Porto Moz - PA, cujo objetivo central foi analisar as prováveis dificuldades encontradas no processo de alfabetização e letramento, a partir da concepção dos alunos. A metodologia utilizada foi a pesquisa de campo com abordagem qualitativa, acrescida de questionário semiestruturado aplicado aos alunos da $2 .^{a}$ etapa da referida escola, que após analisado evidenciou os seguintes resultados: o processo de alfabetização e o letramento ocorrem desarticulados, evidenciando a existência apenas do primeiro ato, já que esse processo não compreende o mundo sociocultural dos estudantes; estes, por sua vez, percebem a aprendizagem da leitura e da escrita a partir da contextualização das práticas sociais, de modo que o indivíduo se torne, ao mesmo tempo, alfabetizado e letrado. E, embora os estudantes da EJA tenham percepção dessa articulação, reconhecem que na escola, há esforço dos docentes por trabalhar as experiências e as vivências comunitárias e profissionais dos alunos.
\end{abstract}

Palavras-chave: Educação de Jovens e Adultos; Letramento. Literatura. Prática social.

\begin{abstract}
This research discusses the possible difficulties faced in the formative path of students of Youth and Adult Education - EJA from a public school in the municipality of Porto Moz - PA, whose central objective was to analyze the probable difficulties encountered in the process of literacy and literacy, from students' conception. The methodology used was a field research with a qualitative approach, plus a semi-structured questionnaire applied to students in the 2nd stage of the school, which after analyzing the following results: the literacy process and literacy occur disarticulated, showing the existence only the first act, since this process does not understand the students' sociocultural world; these, in turn, perceive the learning of reading and writing from the context of social practices, so that the individual becomes, at the same time, literate and literate. And although EJA students are aware of this articulation, they recognize that at school, there is an effort by teachers to work on the students' community and professional experiences.
\end{abstract}

Keywords: Youth and Adult Education; Literacy. Literature. Social practice.

Data de submissão: 04.10 .2020

Data de aprovação: 08.11.2020

\section{INTRODUÇÃO}

A Educação de Jovens e Adultos (EJA) é uma modalidade de ensino destinada aos alunos que não concluíram os estudos no Ensino Fundamental, na idade própria, dura em

\footnotetext{
${ }^{1}$ Doutora em Educação: Currículo pela Pontifícia Universidade Católica - São Paulo. Professora de Didática, Teoria do Currículo e Avaliação Educacional da Faculdade de Educação e colaboradora da Faculdade de Etnodiversidade, da Universidade Federal do Pará (UFPA) Campus Universitário de Altamira. Lattes: http://lattes.cnpq/7426651393268725. ORCID: https://orcid.org/0000-0002-7075-6503. E-mail: irlanda@ufpa.br.

2 Doutora em Educação pela Universidade Federal do Pará. Professora de Práticas de Ensino e Estágio Supervisionado da UFPA/Faculdade de Educação/Campus de Altamira. ORCID:http://orcid.org/0000-00031852-1106 E-mail: leiafreitas@ufpa.br.
} 
média nove anos, como prevê o Capítulo II, Seção V, artigo 37 da Lei de Diretrizes e Bases da Educação Nacional (LDBEN) - Lei no 9394/96, que estabelece: “a educação de jovens e adultos será destinada àqueles que não tiveram acesso ou continuidade de estudos no ensino fundamental e médio na idade própria", cabendo aos sistemas de ensino assegurar gratuitamente oportunidades educacionais apropriadas para o acesso, permanência e conclusão sem perdas, consideradas as "características do alunado, seus interesses, condições de vida e de trabalho, mediante recursos e exames" (BRASIL, 1996).

Na EJA, alfabetizar e letrar vão além da transmissão de conteúdo. É compreender a vivência do aluno e seu cotidiano, por isso requer do professor a compreensão da totalidade das dificuldades preexistentes dos alunos, especificamente no tocante à aquisição da leitura e da escrita. Para Demo (1994), a escola e o professor precisam se interessar pelo aluno, seu mundo, vivências e realidades. É preciso que ele "[...] busque conhecer suas motivações e seus contextos culturais, estabeleça com ele um relacionamento de confiança mútua, tranquila, sem decair em abusos e democratismos. Trata-se sempre de aprender junto, instituindo o ambiente de uma obra comum, participativa" (DEMO,1994, p. 17).

Nesse contexto, "a experiência do aluno será sempre valorizada, inclusive a relação natural hermenêutica de conhecer a partir do conhecido" (DEMO, 1994, p. 17). O respeito pelas diferenças, culturas e os saberes empíricos contribuem para a melhoria do ato educativo, como afirmam Gomes e Garcia (2014, p. 477), isso requer "a compreensão da realidade [sendo] a primeira de inúmeras ações que podemos realizar antes de sugerir mudanças".

Neste contexto problematizamos: Quais as possíveis dificuldades encontradas pelos alunos da EJA, no município de Porto $\mathrm{Moz}$ - PA quanto à alfabetização e ao letramento? $\mathrm{O}$ objetivo geral foi analisar as prováveis dificuldades encontradas no processo de alfabetização e letramento, a partir da concepção dos alunos.

Metodologicamente, trata-se de uma pesquisa de campo com abordagem qualitativa, acrescida da aplicação de questionário semiestruturado, aos alunos do primeiro segmento dessa modalidade, alunos da $2^{\mathrm{a}}$ etapa de uma escola pública municipal da rede escolar do Munícipio de Porto de Moz - PA. Assim, "na condição de princípio científico, a pesquisa [qualitativa] apresenta-se como a instrumentação teórica metodológica para construir conhecimento" (DEMO, 1994, p. 33). Também visa à produção de saberes empírico e conhecimento teórico socialmente fidedigno "que preenche uma lacuna importante em determinada área" (LUNA, 2000, p. 15).

No tocante ao questionário semiestruturado, Severino (2007) aponta como "um conjunto de questão, sistematicamente articuladas, que se destinam a levantar informações escritas por parte dos sujeitos pesquisados, com vistas a conhecer a opinião dos mesmos sobre os assuntos em estudo" (SEVERINO, 2007, p, 125).

Estruturalmente, a composição do artigo está organizada em três seções. Sendo a primeira seção com a contextualização do campo, a caracterização socioeconômica dos alunos a partir das informações contidas no Projeto Político Pedagógico da escola e a análise sobre as metodologias utilizadas pelos professores durante a alfabetização e o letramento.

A segunda seção refere-se à análise dos dados coletados através do questionário sobre as dificuldades encontradas pelos docentes da Educação Jovens e Adultos, sob o alhar dos estudantes. Por fim, a terceira seção apresenta as considerações finais com os resultados alcançados na pesquisa.

\section{ALFABETIZAÇÃO E LETRAMENTO NA CONCEPÇÃO DOS ALUNOS DA SEGUNDA ETAPA DA EJA}

Freire (2001) concebe o processo de alfabetização como a aprendizagem do ato de ler e escrever o mundo criticamente, refletindo um ato político e um ato de conhecimento, no 
qual os educandos são sujeitos e não objetos de sua aprendizagem. A alfabetização de jovens e adultos se constrói a partir das necessidades destes, suas especificidades e trajetórias Assim, é preciso ensinar-lhes a leitura de mundo, o que significa dizer que "o educando pode começar a aprender a ler, a escrever, a contar e se situar no mundo letrado a partir de sua própria vivência" (FREIRE, 2001, p. 18). Conforme os estudos de Tfouni (2002), a alfabetização diz respeito:

[...] à aquisição da escrita enquanto aprendizagem de habilidades para leitura, escrita e as chamadas práticas de linguagem. Isso é levado a efeito, em geral, por meio do processo de escolarização, portanto, da instrução formal. A alfabetização pertence, assim, ao âmbito do individual (TFOUNI, 2002, p.9).

Com posições diferenciadas, mas com princípios formativos comuns, Freire (2001) e Tfouni (2002) concordam que o ato de ler e escrever é mais que saber copiar do quadro. $\mathrm{O}$ conhecimento é construído por meio das interações socioculturais, respeitando as diversas experiências dos educandos.

Ao se posicionar sobre essa questão, Soares (2003) defende que a alfabetização se difere do letramento. Para a autora, alfabetizar e letrar são processos diferentes, mas articulados, na medida em que alfabetização e letramento se complementam, pois, a alfabetização é um componente do letramento. Nessa perspectiva, a leitura e escrita precisam ser trabalhados de modo que o indivíduo não somente decodifique o sistema alfabético, mas compreenda o que lê. Isso requer dos professores, qualificação e atenção às demandas formativas dos estudantes. De acordo Ribas e Soares (2012, p. 5):

[...] faz-se necessário uma qualificação dos profissionais envolvidos neste processo. É fundamental que a equipe docente esteja bem preparada, por este motivo é extremamente importante uma formação continuada, onde todos tenham a oportunidade de repensar a sua prática. Pois, a formação continuada é um processo possível para a melhoria da qualidade do ensino, dentro do contexto educacional contemporâneo.

Para as autoras, a formação continuada dirigida aos docentes que atuam nas turmas de EJA é determinante para uma aprendizagem mais significativa. Nesta conjuntura, o artigo 67 da Lei de Diretrizes e Bases - Lei n. ${ }^{\circ}$ 9394/96 prevê que os sistemas de ensino devem promover a valorização dos profissionais da educação, bem como o aperfeiçoamento profissional continuado.

Para atender essa demanda, em 2002 foi aprovada as Diretrizes Curriculares Nacional de Formação dos Professores da Educação Básica. No artigo $1^{\circ}$ prevê a referida Lei que a formação de professores da Educação Básica far-se-á ao nível superior, em curso de licenciatura e se constitui como "um conjunto de princípios, fundamentos e procedimentos a serem observados na organização institucional e curricular de cada estabelecimento de ensino" (BRASIL, 2001, p. 1).

Entretanto, nos muitos municípios brasileiros, em especial na região da Transamazônica e Xingu, no Sudoeste Paraense, ainda encontramos professores atuando na EJA com formação inadequada e pouco conhecimento teórico-prático sobre essa modalidade de ensino, tal como afirma Gadotte; Romão (2002, p. 122):

Os professores que trabalham na EJA, em sua quase totalidade, não estão preparados para o campo específico de sua atuação. Em geral, são professores leigos ou pertencentes ao próprio corpo docente do ensino regular. Note-se que, na formação de professores, em nível médio e superior, não se tem observado preocupação com o campo específico da educação de jovens e adultos. Deve-se também considerar as precárias condições de profissionalização e de remuneração dos docentes. 
No entendimento de Guedes; Monteiro (2011), o professor deve estar preparado para interagir com seus alunos, estabelecendo com eles diálogo, problematizando e refletindo questões atuais e históricas, bem como sua prática docente. Assim,

[...] a formação continuada deve ser desenvolvida de modo a favorecer ao professor o autoconhecimento da sua prática e a possibilidade de refletir sobre as atividades de ensinar e de aprender no contexto da educação, superando assim os modelos que se ocupam de treinamentos, reciclagens e atualizações que muitas vezes são realizados e que em pouco ou quase nada contribuem nesse processo de se autoconhecer Guedes e Monteiro (2011, p. 11).

A formação continuada possibilita ao professor aperfeiçoamento, por conseguinte, abre um leque de novos saberes e conhecimentos, bem como, melhora a prática e inova as estratégias metodológicas. Em Porto de Moz, essa prerrogativa, na concepção dos atores pesquisados, foi um balizador importante, já que para eles a falta de formação continuada acerca das estratégias metodológicas sobre as especificidades da EJA tem contribuído para a desistência/evasão escolar de muitos alunos, como evidenciado na Proposta Pedagógica da escola. Além dessas evidências o referido documento também apontou:

1) que a escola atende 784 alunos, desse total, 180 estão matriculados na EJA. Esses alunos são oriundos de quatro bairros da periferia da cidade, sendo a maioria carente e com família numerosa, pais não alfabetizados, desempregados e muitas famílias são beneficiários do Programa do Governo Federal, Bolsa Família; 2) a escola é de médio porte contendo dez salas de aula, laboratório de informática, espaços para leitura, atividades administrativas, de gestão e de coordenação pedagógica; 3) a escola tem como missão desenvolver uma educação de qualidade, [...], priorizar uma educação articulada ao mundo sociocultural dos alunos, o envolvendo as famílias e a comunidade, com o intuito de formar cidadãos conscientes de seus direitos e deveres perante uma sociedade que está a cada época mais exigente em relação à qualificação profissional; 4) os planejamentos são realizados pelos docentes tendo como base as necessidades educativas do aluno no ato da matrícula, buscando a efetivação de um ensino eficaz que gera aprendizagens significativas; 5) o cotidiano desses jovens e adultos se divide entre as atividades escolares e extraescolares, subdivididas em projetos educativos existentes na escola, aulas de informática e projetos sociais, ofertado pela Secretaria Municipal de Ação Social (SEMUTS) e realizados no contraturno. Projetos como "Banda Marcial" e "Amigos da paz", acontecem durante o ano letivo, com diversas apresentações, cujo objetivo é possibilitar ao aluno, processos de socialização, educação e formação cidadã; 6) os alunos da EJA são trabalhadores e muitos chegam à escola, desmotivados, outros sem histórico de escolaridade. Sentem-se perdidos em relação à escola, à aprendizagem da leitura e da escrita e dos conteúdos escolares. Também há registros de alcoolismo, casamento e problemas de saúde. Alguns alunos infelizmente não tiveram e não tem incentivos dos pais para continuar a vida escolar. Porém, há àqueles que sonham com a continuidade da vida acadêmica; 7) Sobre a formação das professoras, identificamos que elas têm curso superior em Licenciatura em Pedagogia; estão há mais de quinze anos na profissão e a mais de cinco trabalham com essa modalidade de ensino (PPP, 2015).

A partir desse levantamento no PPP da escola, buscamos identificar qual a percepção dos alunos acerca da atuação prática de seus professores. Para eles, elas [professoras] são profissionais comprometidas com a aprendizagem e com a escola. Os alunos afirmaram que as professoras defendem que a escola é um espaço de acolhimento, permitindo a participação ativa de todos. A escola é um espaço de aprendizagens, aberta "[...] ao acolhimento dos alunos, que é alguém especialmente receptivo à aprendizagem, repleto de curiosidades e que vai para a sala de aula desejoso de novas experiências, como, por exemplo, aulas interativas, 
criativas, reflexivas, fáceis e participativas" (SOUSA; CUNHA, 2010, p. 03), questões importantes para o trato da alfabetização e do letramento.

Essa ideia corrobora com os dados identificados, já que na concepção dos alunos, na escola eles aprendem a ler, a escrever e a interpretar textos mais facilmente, devido às metodologias usadas pelos professores. Neste caso, questionamos: você ver diferença entre alfabetizar e letrar? (J. V. S, 2019) afirma: "sim, pois a alfabetização é o ato de aprender a ler e a escrever. Já o letramento, relaciona-se a interpretação dos diversos textos". Na concepção deste discente a alfabetização está direcionada apenas ao ato de ler e escrever, contudo, lembramos que ela é sistêmica, contínua, assim como o letramento e, nesse processo, ambos se complementam, bem como afirma (M. F, 2019) "letramento está associado à alfabetização, à leitura da nossa realidade". Essa concepção se assemelha ao pensamento de Soares (2001), ao afirmar que alfabetização e letramento pressupõem "ensinar a ler e a escrever no contexto das práticas sociais da leitura e da escrita, de modo que o indivíduo se torne, ao mesmo tempo, alfabetizado e letrado" (SOARES, 2001, p. 47).

Essas percepções estão ligadas as diferentes visões de mundo dos alunos, bem como, de suas diversidades de saberes e conhecimentos socioculturais, sendo, portanto, um desafio aos professores, pois, foi identificado nos trechos dos questionários relatos que indicam a dificuldade dos professores em estabelecer essa relação, na prática e nas estratégias metodológicas utilizadas durante as aulas. Houve indícios também do esforço dos docentes por trabalhar o contexto do aluno, sua vivência comunitária e profissional, como afirma (N. P. A, 2019): "alguns utilizam muitas atividades como leituras de jornais, revistas, livros, jogos de palavras e números. Às vezes trabalham com nossa realidade". Nesse sentido, Gasparin (2001, p. 8) lembra que esses jovens: "vivenciam a paixão, o sentimento, a emoção, o entusiasmo, o movimento. Anseiam por liberdade para imaginar, conhecer, tudo ver, experimentar, sentir".

Quanto ao planejamento escolar, o estudante (T.L.M, 2019) diz que "quando os professores dão muitas atividades e diferentes, penso que ela planeja bem suas aulas". Isso indica a existência do ato de planejar pela docente e a percepção desse ato pelo aluno. Para Vasconcellos (2000), somente por meio do planejamento que a definição dos objetivos, metodologias, avaliação e outros elementos do fazer docente são materializados. O professor ao se planejar estabelece propósitos, escolhe melhor os materiais didáticos e os métodos a serem usados, pois, ele é um instrumento que permite intervenção, direciona o trabalho e organiza as ações didáticas. Nos dizeres do autor:

O planejamento deve ser compreendido como um instrumento capaz de intervir em uma situação real para transformá-la. Como vemos fica reservado ao planejamento à função de direcionar o trabalho de forma que esta aconteça de forma consciente e capaz de organizar e proporcionar mudanças (VASCONCELLOS, 2000, p. 34).

O planejamento deve conceber a realidade dos educandos, de modo a transformá-la. Noutros termos, significa que o planejamento consiste na valorização das atividades, possibilita a reflexão reconstruída quando necessária. Isso porque um planejamento consistente e viável permite ao aluno à apropriação da alfabetização e do letramento de forma mais rápida e segura, pois, há a apropriação da linguagem escrita e da leitura, por meio de atividades metodológicas pensadas para eles.

Como estratégia didática, o planejamento oportuniza pensar em atividades específicas para determinados alunos, de saber o melhor momento para a intervenção didática, considerar os níveis de aprendizagens e limites dos alunos, pois se trata de "[...] uma ação reflexiva, viva, continua. Uma atividade constante, permeada por um processo de avaliação e revisão sobre o que somos" (FARIAS et al, 2009, p.107). Há que se considerar ainda problemáticas sociais e políticas da sociedade, assim como o cotidiano e a curiosidade do educando, tal como propõe 
Freire (1999, p. 18): ao afirmar que na educação requer formas interessantes de trabalho, debater questões sociais e políticas e a "curiosidade dos educandos".

Na orientação de Freire (1999), o planejamento deve partir da realidade dos educandos e em seguida da organização do professor em relação a esta realidade, problematizando a vivência dos alunos, a importância dos conteúdos, as experiências e o contexto dos sujeitos. Como exemplifica Freire (1986, p. 23):

\begin{abstract}
A palavra tijolo, por exemplo, se inseriria numa representação pictórica, a de um grupo de pedreiros, por exemplo, construindo uma casa. Mas, antes da devolução, em forma escrita, da palavra oral dos grupos populares, a eles, para o processo de sua apreensão e não de sua memorização mecânica, costumávamos desafiar os alfabetizando com um conjunto de situações codificadas de cuja decodificação ou "leitura" resultava a percepção crítica do que é cultura, pela compreensão da prática ou do trabalho humano, transformador do mundo. No fundo, esse conjunto de representações de situações concretas possibilitava aos grupos populares uma "leitura" da "leitura" anterior do mundo, antes da leitura da palavra.
\end{abstract}

Devido a sua singularidade, a educação de jovens e adultos, não podem pautar-se em práticas bancárias ${ }^{3}$ de educação, porque é uma clientela que por motivos diversificados de negações de direito não conseguiram acesso às políticas educacionais na idade certa, resultando em demandas educativas que necessitam de acompanhamentos específicos. Neste sentido, uma das questões investigada foi a maior dificuldade percebida pelo aluno durante as aulas, (J.P, 2019) respondeu: "aprender os conteúdos; muitos de nós não entendemos o que o professor está querendo repassar, pois, está fora da nossa realidade".

A organização pedagógica-curricular no cotidiano da EJA e seus desdobramentos na prática educativa, em Porto de Moz, se caracteriza pelas orientações da Secretaria Municipal de Educação (SEMED), fundamentado no modelo da Secretaria de Estado de Educação do Pará (SEDUC/PA), no entanto, tanto a equipe pedagógica quanto a equipe de professores são orientados a realizarem diagnósticos junto aos alunos para adequar o ensino a realidade local.

Um problema apresentado por Brandão; Feitosa; Amaral (2009) na organização pedagógica-curricular, geralmente é confundida pelas escolas como currículo, mas eles são conhecimentos científicos que por vezes, desarticulados dos saberes de mundo. Desconsideram-se nesse processo os conhecimentos e os saberes já adquiridos, suas experiências e vivências socioculturais, pois, "[...] bem mais do que distribuir alguns saberes temáticos ao longo de um tempo de estudos, precisa integrar estes saberes, a serem ensinados com as experiências de vida trazidas pelos participantes da comunidade aprendente de uma turma de EJA" (BRANDÃO; FEITOSA; AMARAL, 2009, p. 20).

Não basta a transferência de conhecimentos, a EJA requer um "currículo" contextualizado, integrando espaços/tempos dos alunos, diálogo entre culturas e interação entre saberes empíricos e os conhecimentos das diversas áreas de ensino. O currículo é o ponto de partida para uma educação de qualidade, conhecer os anseios dos alunos da EJA por meio do diálogo é estabelecer uma oportunidade de aprendizagem e experiências entre culturas através de pessoas, de modo que viabilize sempre a qualidade de ensino.

É integrar espaços/tempos educativos, de tal modo que através de encontros de vidas, de identidades, de afetos, de saberes individuais e de significados culturais, pessoas em interação dialoguem e, assim, mutuamente se ensinem e aprendam.

\footnotetext{
3 "Na visão bancária da educação, o saber é uma doação dos que se julgam Sábios aos que julgam nada saber. Doação que se funda numa das manifestações instrumentais da ideologia da opressão - a absolutização da ignorância, que constitui o que chamamos de alienação da ignorância, segundo a qual esta se encontra sempre no outro" (FREIRE, 1999, p. 33).
} 
Elaborar um currículo é trazer para um campo da educação momentos e dimensões de uma cultura. De um modo de vida próprio de uma comunidade cultural, que deve ser retraduzido e sintetizado em um currículo, como uma proposta de saberes e sentidos que devem ser dialogicamente ensinados e aprendidos (BRANDÃO; FEITOSA; AMARAL, 2009, p. 20).

A reflexão sobre o currículo demanda uma análise mais profunda das concepções sobre a escola, sobre os sujeitos e sobre as intenções educativas da instituição escolar. $\mathrm{O}$ currículo em sua perspectiva mais ampla não se acentua somente nas dimensões técnicas e instrumentais elencadas pelos professores, mas nas concepções de educação e de mundo dos sujeitos. Para Sacristán (2013, p.34), o currículo é "o projeto seletivo de cultura, social, política e administrativamente condicionado, que preenche a atividade escolar e que se torna realidade dentro das condições da escola tal como se acha configurada".

Nas vozes dos alunos, uma das justificativas utilizadas pelos professores para o ensino da matriz curricular proposta pela SEMED é a transmissão do conhecimento científico, porém, (A. M, 2019) quer mais, para ela os "professores devem ensinar o que é importante para a vida". Sobre a questão proposta, indica Brasil (2001, p.163):

\begin{abstract}
A complexidade da vida moderna e o exercício da cidadania plena impõem o domínio de certos conhecimentos sobre o mundo a que jovens e adultos devem ter acesso desde a primeira etapa do ensino fundamental. Esses conhecimentos deverão favorecer uma maior integração dos educandos em seu ambiente social e natural, possibilitando a melhoria de sua qualidade de vida.
\end{abstract}

Somente assim é possível pensar num processo formativo completo. Compreendemos a partir de Brandão (2002, p. 76) que "a educação deve ser pensada e deve ser praticada como um cenário multifocal de experiências culturais, de trocas de vivências destinadas à criação de saberes e à partilha da experiência do exercício inacabável de aprender". Quanto ao questionamento aos alunos: Você tem dificuldades na escola, se sim, quais? "não aprendi a interpretar textos (R. M. S., 2019); "gostaria de aprender a fazer carta e redação" (P. G. B, 2019); "não sei fazer continhas e escrever textos" (A. F., 2019); "minha dificuldade é ler e escrever, por enquanto, mas acredito que vou melhorar" (P. F. A., 2019). Nessas falas, percebemos que os alunos têm diversas dificuldades relacionadas à alfabetização e ao letramento. Isso nos faz lembrar Freire (2001, p. 11) ao afirmar que: "[...] a leitura do mundo precede a leitura da palavra, daí que a posterior leitura desta não possa prescindir da continuidade da leitura daquele [...] a compreensão do texto a ser alcançada por sua leitura crítica implica a percepção das relações entre o texto e o contexto" (FREIRE, 2001, p. 11).

Freire (2001) ainda reforça que longos períodos de ausência da escola, contribuem para as dificuldades apresentadas pelos alunos, além disso, velhas práticas docentes, sem reflexão da realidade e sem o exercício da ação do fazer acabam por influenciar no processo de aprendizagem, assim faz-se necessário refletir na/pela ação, já que esses sujeitos concretos, flutuantes e inacabados, têm especificidades múltiplas.

Para superar esse distanciamento, deve o educador envolver-se com a realidade do educando, ouvir suas experiências e planejar seguindo princípios dialógicos; além disso, sua prática educativa deve ser subsidiada com auxílio de materiais didáticos que representam e façam sentido para a vida dos alunos, proporcionando momentos reflexivos que contribuem para uma aprendizagem mais libertadora e motivada. 


\title{
2 DIFERENTES OLHARES SOBRE O PERCURSO FORMATIVO DO ALUNO DA EJA
}

$\mathrm{Na}$ vivência da escola, afirmam os alunos, sentir dificuldades, cita-se a falta de incentivo para permanecer na escola, pois, o que se aprende raramente se associa com a realidade e o mundo sociocultural, causando reprovação e desistência. Nesse sentido, perguntamos a eles quais as principais dificuldades que os impediram de continuar os estudos?

\begin{abstract}
$\mathrm{Na}$ verdade, eu tive que escolher entre trabalhar e estudar. Eu estudei até a $4^{\mathrm{a}}$ série e desisti, pois eu morava no interior e mexia com roça. O que me fez desistir de estudar foi que eu chegava muito cansado na sala de aula e às vezes eu dormia na sala, e a professora não passava assuntos muito interessantes. Aprendi a ler e escrever um pouco com o meu pai (A. F., 2019);

Meus pais sempre trabalhavam na roça, eu estudei até a $3^{\text {a }}$ série e não tive, mas condições de frequentar as aulas. Me casei e tive filhos muito cedo, por esses motivos não tive tempo de estudar, meu marido sempre me incentivava a ir à escola, mas meu dia era muito cansativo (S. A., 2019).
\end{abstract}

Esses relatos indicam vários fatores que contribuíram para o insucesso da vida escolar dos alunos, uns casaram cedo, isso exigiu cuidados com a família e maior dedicação ao trabalho; outros, não tiveram os incentivos, por isso sentem-se desvalorizados.

O aluno trabalhador que frequenta as classes noturnas do supletivo normalmente já passou por várias experiências escolares. Essas experiências geraram no aluno sentimentos de incapacidade e desvalorização pessoal. Esses estigmas na escola autoritária são reforçados em várias situações da prática pedagógica do professor (ABRANTES, 1991, p.34).

A partir disso, nos interessou saber: por quais motivos você decidiu voltar a frequentar a escola? "um dos motivos foi à dificuldade para conseguir um emprego" (R. M., 2019); "terminar meus estudos e fazer um concurso público" (A.F, 2019); "meus pais são analfabetos, isso me fez refletir muito" (P. G. F., 2019). Isso para Gadotti (2008) está ligado à sobrevivência:

[...] os jovens e adultos trabalhadores lutam para superar suas condições precárias de vida (moradia, saúde, alimentação, transporte, emprego, etc.) que estão na raiz do problema do analfabetismo. Para definir a especificidade de EJA, a escola não pode esquecer que o jovem e o adulto analfabeto é fundamentalmente um trabalhador - às vezes em condição de subemprego ou mesmo desemprego [...] (GADOTTI, 2008, p.31).

Os alunos da Educação de Jovens e Adultos têm um traço de vida bastante incomum em relação à escolaridade: a situação socioeconômica, o fator geracional e ritmos de aprendizagem, mas, pensam diferentes. A que se considerar que esses traços se manifestam multifacetado no cotidiano da escola, causando-lhes vergonha e constrangimentos. "Às vezes riem de mim porque já passei da idade de estudar" (A. G. F., 2019); "fico constrangido por estar na EJA" (S. A, 2019); "algumas pessoas que trabalham aqui na escola nos olham de uma forma muito diferente, não sei porquê" (A. M, 2019); "vejo meninas da minha idade que fazem ensino médio e outras até faculdade, minha prima tem a minha idade e já é até professora" (P. F. A., 2019). Para Arroyo (2011), esses sujeitos trabalhadores vivem o mundo do trabalho e esquecem a escola, são alunos com responsabilidades sociais e familiares, com valores éticos e morais cultivados a partir de seus conhecimentos empíricos, do ambiente e da 
realidade sociocultural em que estão inseridos e isso deve ser relevado no processo educacional.

[...] essas diferenças podem ser uma riqueza para o fazer educativo. Quando os interlocutores falam de coisas diferentes, o diálogo possível. Quando só os mestres tem o que falar não passa de um monólogo. Os jovens e adultos carregam as condições de pensar sua educação como diálogo. Se toda educação exige uma deferência pelos interlocutores, mestres e alunos (as), quando esses interlocutores são jovens e adultos carregados de tensas vivências, essa deferência deverá ter um significado educativo especial (ARROYO, 2011, p.35).

Ao optarem por dar continuidade à vida escolar, os jovens e os adultos anseiam por uma educação voltada para o diálogo. Muitas vezes, trata-se de um processo contínuo de idas e vindas, de ingressos e desistências. Ir à escola para esses homens e mulheres é antes de tudo, um desafio, um projeto de vida. O espaço escolar é lugar de satisfação, um ambiente de transformação para o acolhimento dos sujeitos curiosos, buscando novas experiências, como, por exemplo, aulas interativas, criativas, reflexivas, fáceis e participativas, exigindo do professor, responsabilidades com as aprendizagens. Nesta perspectiva, assevera Freire (1996, p. 73):

\begin{abstract}
A responsabilidade do professor é sempre grande. Sua presença na sala é de tal maneira exemplar que nenhum professor escapa ao juízo que dele fazem os alunos. Seja quem for o professor: autoritário, sério, incompetente, irresponsável, licencioso, mal amado, com raiva do mundo, burocrático, frio, amoroso [...] nenhum deles passa pelos alunos sem deixar sua marca.
\end{abstract}

$\mathrm{Na}$ sala de aula, a timidez, retração e vergonha em participar das aulas, são características comuns. Fatores como vergonha do professor e a relação conturbada entre professor-aluno pode interferir no processo de aprendizagem. O papel do professor é decisivo para que ambos se sintam bem, assim, nos interessou saber como se dava a relação, professoraluno em sala de aula, e se essa relação influenciava ou dificultava na alfabetização e no letramento:

\begin{abstract}
Minha relação com a professora é muito amigável, acho por que eu costuro algumas roupas pra ela (risos), essa relação me ajuda bastante na aula, por que eu me sinto mais à vontade com ela, eu acho que se fosse com outro professor não seria assim (R. B. S., 2019);

Sou tímido, mas sempre que eu preciso dela ela me ajuda, onde ela me ver na rua ela fala comigo, pra mim ela é uma ótima professora (P. G. B., 2019);

Eu sou bem entrosada com a professora, ela me dar conselhos (A. G. F., 2019);

Eu tenho pouca intimidade com a pessoa, mas na sala de aula ela me dar à devida atenção, isso acaba me ajudando na hora de completar minha atividade (P. S., 2019).
\end{abstract}

Percebemos a partir dos relatos, que a relação, professor e aluno fundamentam-se no respeito, diálogo e proximidade como destacado por Freire (1999), ao afirmar que a relação de ensino e aprendizagem deve ser alicerçada no diálogo, de modo a superar práticas de autoritarismo no cotidiano escolar. Situação a ser considerada, pois, a desmotivação causada pelas sucessivas desistências e até mesmo por reprovação marcam as vivências escolares. A partir do enunciado questionamos aos alunos se depois de terem retornado à escola, pensaram em desistir, se sim, por quê? Eles responderam:

Não. Por que hoje eu sei o quanto é importante estudar, a aprender a fazer o nome da gente e ler jornais, revista, bíblia e principalmente ensinar meus filhos (R. M. S., 2019); 
Não. Pois quero realizar meu sonho de ser policial, e só vou conseguir se eu estudar (P. M. G., 2019);

Não. Por que se eu estudar eu vou conseguir um emprego melhor e comprar uma casa pra mim. Mas penso que os professores deveriam fazer aulas mais dinâmicas para nos incentivar (A. F., 2019).

Apesar das dificuldades, os alunos são unanimes em pontuar que não pensam em desistir da escola, mas alertam sobre a importância de metodologias e materiais didáticos mais atraentes para uma aula mais dinâmica e prazerosa. Perguntamos então sobre a qualidade dos recursos didáticos e a frequência com que são usados em sala de aula:

Materiais são poucos, às vezes a professora muda o jeito de dar e aprendo mais fácil (J. V. S., 2019);

Eu não gosto quando ela só escreve na lousa, gosto quando ela traz jogos e brincadeiras (P. F. A., 2019);

Ela traz esses novos meios de ensinar para facilitar a nossa aprendizagem. (S. A., 2019);

Acho divertido quando ela faz brincadeiras sobre os assuntos que ela passa pra gente (P. F. F., 2019).

As professoras se esforçam para utilizar diversas metodologias e os poucos recursos existentes para dinamizar as aulas e propor estratégias diferenciadas, tornando-as mais lúdicas e envolventes. Nesta acepção, afirmam Costa, Álvares; Barreto (2006, p. 11):

Os jovens e adultos buscam na escola, sem dúvida, mais do que conteúdos prontos para serem reproduzidos. Como cidadãos e trabalhadores que são, esses alunos EJA querem se sentir sujeitos ativos, participativos e crescer cultural, social e economicamente.

Essas ações aproximam os sujeitos ao mesmo tempo, em que facilita a aprendizagem dos conteúdos propostos. Ao realizar isso, os professores possibilitam aos alunos, múltiplos olhares acerca do cotidiano escolar, das trajetórias humanas, da diversidade sociocultural e outros fatores que interferem no percurso formativo do aluno da EJA. Questão a ser consideradas em função das heterogeneidades:

[...] os sujeitos da EJA hoje são diversos: trabalhadores, aposentados, jovens empregados e em busca do primeiro emprego; pessoas com necessidades educativas especiais, para citar alguns. Daí decorre também a preocupação com o conceito de diversidade cultural no contexto da EJA. Os sujeitos da EJA atualmente são o trabalhador experiente e o jovem com outro tipo de experiência no mundo (SOUZA, 2011, p. 20).

Essas diferenças qualifica o cenário escolar, melhora a aprendizagem e facilita o domínio das vivências. Esses indivíduos buscam na escola, motivos para o sucesso pessoal e profissional, como percebido nas falas dos estudantes (R. M. S, 2019) e (A. F, 2019) quando se referem aos motivos do regresso ao mundo das letras, seja, melhores oportunidades de trabalho, realização de um sonho ou melhores qualidades de vida. Porém, quando retornam à escola, muitos se deparam com outra realidade, convivem com pessoas de diversas idades, comportamentos, temperamentos, ideias e desejos.

Ao docente, cabe a tarefa de melhorar esse ambiente, por vezes hostil e facilitar o convívio por meio do diálogo, da inovação das aulas, da proximidade sociocultural e por fim, do comprometimento ético e político tão necessário atualmente. Partindo disso, perguntamos aos alunos se a diferença de idade, cultura, classe social ou comportamentos interferem nas aulas, a maioria afirmou não enfrentar esses problemas, mas, apresentaram questões 
relevantes para o debate, como observado nas falas de (R. M. S, 2019), (M. F, 2019) e de (P. M. G, 2019), respectivamente:

Esses problemas não tenho, mas tenho vista curta. Outra coisa que me incomoda é o barulho do ventilador, me dar dor de cabeça de vez enquanto);

Sinceramente chegar cansado na sala de aula, essa é o meu maior problema.

A falta de material didático, principalmente os livros.

Para esses alunos, os maiores problemas e dificuldades encontradas no cotidiano da escola, além dos já pontuados anteriormente, referem-se à estrutura da escola, o cansaço e problemas pessoais. Para eles, esses aspectos causam desinteresses e dificultam o desenvolvimento do educando. Também identificamos a indicação do fato em conciliar família, trabalho e escola. Tais questões dificultam o acesso, permanência e o sucesso escolar desses sujeitos.

\begin{abstract}
Além das dificuldades de acesso e permanência na escola, os jovens enfrentam a realidade de instituições públicas [...], isso implica em dizer que as escolas têm se apresentado como instituições pouco abertas para a criação de espaços e situações que favoreçam experiências de sociabilidade, solidariedade, debates públicos e atividades culturais e formativas de natureza curricular ou extraescolar (CARRANO, 2007, p.60).
\end{abstract}

As questões levantadas pelos alunos e reforçadas nos estudos de Carrano (2007) evidenciam problemas e dificuldades existentes no cotidiano da EJA em Porto de Moz. Considerando que para o autor elas se manifestam desde o ingresso do aluno à instituição, até sua saída, aconselha-se à escola e aos professores, o desenvolvimento da sensibilidade e o princípio da empatia. Ao ter que lidar com uma série de problemáticas cotidianas, os alunos quase sempre acaba por transferir tais questões para o âmbito do acadêmico, prejudicando, portanto, sua continuidade na escola e as condições de aprendizagem tornam-se desfavoráveis, perpassando pelo currículo escolar que ofertam conteúdos que não condizem com a realidade dos alunos. Assim, indagamos: a falta da escola e dos estudos tem prejudicado sua vida, se sim, como?

Sim. Se eu não estivesse parado de estudar com certeza hoje eu teria uma condição de vida melhor e não pediria para que os outros lessem pra mim. (R. M. S., 2019);

Sim. De maneira que fez perder várias oportunidades de emprego e até mesmo de concursos públicos aqui da cidade (A. F, 2019);

Sim. De maneira que me fez de deixar realizar muitas coisas na minha vida. (S. A., 2019).

Para os entrevistados, a falta de estudo é condicionadora de prejuízos pessoais e profissionais, dificulta a realização de sonhos, além de impedir a melhoria de vida. Medeiros (2008, p. 19), ao refletir sobre a situação afirma que:

Jovens e adultos, mulheres ou homens que deixaram de estudar em outros momentos, ao buscar a EJA demonstram arrependimento ou mesmo vergonha, buscando agora a oportunidade de concretizar projetos de crescimento pessoal e profissional. Mas ao mesmo tempo, demonstram orgulho de sua condição de agora estudante, de alguém que está correndo atrás do tempo perdido.

Para a autora, apesar do tempo perdido, os alunos da EJA sentem orgulho por ter voltado à escola, e por se tornar aluno outra vez, mas isso não os impede de viver dificuldades. Sem apoio e incentivo de familiares, amigos, escola e dos professores, fadam-se ao fracasso, como expressa (A. M, 2019): "muitos alunos desistem, depois do retorno à escola 
porque não tem apoio da escola, direção e coordenação e também dos professores, já sentimos falta do apoio da família, sem não puder contar com a escola, como fazer?".

Outros alunos também manifestam essa preocupação:

A falta de incentivo da escola, tanto para nós, quanto para os professores é difícil. Por vezes eu fico olhando alguns funcionários e percebo que não estão nem aí pra gente, a professora trabalha de forma muito sozinha, essa é a minha opinião, apesar disso nos esforçamos muito (S. A., 2019).

Perguntamos para os alunos, o que era um aluno esforçado, para eles e para os professores, (J. V. S, 2019), responde:

[...] para alguns professores, um aluno esforçado é aquele que faz todas as atividades escolares e não falta, mas temos as limitações das rotinas diárias, para mim a escola precisa ter mais atenção quanto ao acompanhamento da turma, formada por alunos entre 18 e 38 anos, com histórias de vidas diversas, e ainda, com níveis de conhecimentos diferentes.

Não considerar esse processo é alijar a aprendizagem do aluno, suas histórias, os diferentes conhecimentos e as múltiplas experiências. Isso para nós prejudica a construção e o desenvolvimento da leitura e da escrita de forma própria, não primando por um letramento e alfabetização de forma dinâmica, significativa e consistente. Ao contrário, sentem-se os alunos desmotivados em não corresponder às expectativas da sociedade, da escola e, principalmente, dos docentes, "muitas vezes, a escola e os professores não acreditam em nós, acham que somos incapazes para aprenderem" (M. F. (2019).

Abrantes (1991, p.34), chama nossa atenção para a questão quando afirma que:

[...] a baixa expectativa que o professor tem sobre o aluno também reforça a sua auto desvalia: aligeirar o conteúdo, porque o futuro lhe reservou apenas essa 'chance' de estudar: acreditar que esses alunos são menos inteligentes que os da escola particular; imaginar que jamais poderão ascender profissionalmente face à sua incapacidade intelectual, é terrível.

Nessa mesma linha de pensamento, Di Pierro (2001) problematiza a situação do alunotrabalhador ao pontuar que em muitos estados brasileiros, em função da localização das escolas, difícil mobilidade dos alunos e garantia à segurança, as aulas são reduzidas, isso contribui para desistência e evasão, como percebemos na fala de um aluno: as aulas reduzidas são ruins. "Muitos alunos chegam tarde à sala de aula por causa do serviço e a professora ainda libera mais cedo, pela dificuldade de os alunos voltarem para casa muito tarde, isso às vezes é desestimulador" (T. L. M., 2019).

Todavia, reflete sensibilidade do professor, já que para Di Pierro (2001, p. 122) “é preciso pensar em um modelo de escola mais flexível e conectada com a vida".

\section{CONSIDERAÇÕES FINAIS}

A educação de jovens e adultos no Brasil é um grande desafio. Em Porto de Moz, isso não se difere, já que muitas lutas existem para que não haja desistência, evasão e retrocesso no processo de ensino e aprendizagem. As perdas e os danos são resultados da provação e da negação de direitos aos homens e mulheres desejantes de estudos diversificados, voltados às múltiplas aprendizagens e uma educação diversificada.

Atenção às especificidades desses alunos é cogente, pois se trata de trabalhadores e trabalhadoras, que em razão do não acesso à escola na idade própria, retornam aos estudos buscando melhor sua vida pessoal e profissional. 
A complexidade da modalidade acentua-se na riqueza de saberes, conhecimentos empíricos e experiências que transforma suas vivências, dificultando aos professores a compreensão de uma educação mais flexível, dinâmica e contextualizada. Situação proveniente, da formação docente, das políticas públicas e da falta de sensibilidade e alteridade em ver e entender o mundo da EJA, como ricas possibilidades de mudanças teóricas e práticas da ação docente.

Em relação ao processo de Letramento e Alfabetização da EJA, destacamos várias questões, a saber:

O uso de práticas e métodos tradicionais de leitura e escrita interferem no processo de uma aprendizagem significativa, assim, cabe ao professor a utilização de meios, técnicas e estratégias inovadoras para incentivar ao hábito da leitura e escrita. A necessidade de se (re) inventar é preciso, já que os estudantes se sentem desestimulados.

A alfabetização e o letramento ocorrem desarticulados da realidade dos alunos, evidenciando a existência apenas do primeiro ato, já que esse processo não compreende o mundo das vivências e das experiências dos sujeitos pensantes, multifacetados e complexos, evidenciando uma ampla descontextualização das práticas sociais, culturais e políticas.

Contudo, há por parte dos alunos o reconhecimento dos esforços da escola e dos professores em abordar situações vivências da comunidade e da sociedade durante as aulas, embora isso ocorra sutilmente.

Em razão de inúmeros fatores como falta de incentivo familiar, escolar e dos próprios docentes, além do trabalho, mobilidade e segurança, acabam desistindo, mesmo sabendo da importância de estudar.

\section{REFERÊNCIAS}

ABRANTES, Wanda Medrado. A didática da educação básica de jovens e adultos: uma construção a partir da prática do professor. Rio de Janeiro, 1991.

ARROYO, Miguel González. Educação de Jovens e Adultos: um campo de direitos e de responsabilidade pública. In: NOGUEIRA, Paulo Henrique de Queiroz; MIRANDA, Shirley Aparecida de (Orgs.). Miguel Gonzáles Arroyo: educador em diálogo com nosso tempo. Belo Horizonte, MG: Autêntica, 2011.

BRANDÃO, Carlos Rodrigues. A Educação Popular na Escola Cidadã. Petrópolis: Vozes, 2002.

BRANDÃO, Carlos Rodrigues; FEITOSA, Sonia Couto Souza; AMARAL, Rutléa. Princípios curriculares orientadores para a EJA. In: Enceja Caderno 2. São Paulo: Instituto Paulo Freire, 2009.

BRASIL. Lei no 9.394, de 20 de dezembro de 1996. Lei de Diretrizes e Bases da Educação Nacional. Diário Oficial [da] República Federativa do Brasil, Brasília, DF, v. 143, n. 248, 23 dez. 1996.

BRASIL. Ministério da Educação. Conselho Nacional de Educação. Parecer no 9 do 8 de maio. de 2001.

BRASIL. Secretaria de Educação do Estado da Bahia. Plano Plurianual de Alfabetização. Salvador/BA, 2007. Disponível em: http:www.sec.ba.gov.br/topa/ppalfa2007. Acesso em: dez. de 2019. 
BRASIL. Educação para jovens e adultos: ensino fundamental: proposta curricular. $1^{\circ}$ segmento /coordenação e texto final de Vera Maria Masagão Ribeiro. São Paulo: Ação Educativa; Brasília: MEC, 2001. 239p.

CARRANO, Paulo. Educação de jovens e adultos e juventude: o desafio de compreender os sentidos da presença dos jovens na escola da "segunda chance". Revej@: revista da educação de jovens e adultos, v. 1, n.0, ago. 2007. Disponível em:

www.reveja.com.br/sites/default/files/REVEJ@_0_PauloCarrano.pdf. Acesso em: 20 ago. 2020.

COSTA, Elisabete; ÁLVARES, Sônia Carbonell; BARRETO, Vera. Trabalhando com a Educação de Jovens e Adultos. BRASÍLIA, 2006.

DEMO, Pedro. Pesquisa e construção do conhecimento: metodologia científica no caminho de Habermas. Rio de Janeiro: Tempo Brasileiro, 1994.

DI PIERRO, Maria Clara; JOIA, Orlando; RIBEIRO; Vera Masagão. Visões da Educação de Jovens e Adultos no Brasil. Cadernos, ano XXI. № 55. Novembro de 2001. Disponível em: www.scielo.br/pdf/acedes. Acesso em: 25 de ago. de 2020.

FARIAS, Maria Isabel de. et al. Didática e Docência: aprendendo a profissão. Brasília: Liberlivro, 2009.

FREIRE, Paulo. A importância do ato de ler: em três artigos que se completam. 42. ed. São Paulo: Cortez, 2001. (Questões da nossa época, 13).

FREIRE, Paulo. Medo e ousadia: o cotidiano do professor. 2. ed. Rio de Janeiro: Paz e Terra, 1986.

FREIRE, Paulo. Pedagogia da autonomia: saberes necessários à prática educativa. Rio de Janeiro: Paz e Terra, 1996.

FREIRE, Paulo. Pedagogia da Autonomia: saberes necessários à prática educativa. $12^{\mathrm{a}} \mathrm{Ed}$. Rio de Janeiro: Paz e Terra, 1999.

GADOTTI, Moacir. Educação de Jovens e Adultos: Teoria, Prática e Proposta. 10. ed. São Paulo: Cortez: Instituto Paulo Freire,2008.

GADOTTI, Moacir; ROMÃO, José Eustáquio (Orgs.) Educação de jovens e adultos: teoria, prática e proposta. 5. ed. São Paulo: Editora Cortez, 2002. Guia da escola cidadã; v. 5.

GASPARIN, João Luiz. Motivar para aprendizagem significativa. Jornal Mundo Jovem. Porto Alegre, n. 314, p. 8, mar. 2001.

GOMES, André Taschetto; GARCIA, Isabel Krey. Perfil sócio-educacional de estudantes da Educação de Jovens e Adultos (EJA): um estudo de realidades e interesses acerca do conceito Energia. Departamento de Física, Universidade Federal de Santa Maria (UFSM), 2014. 
GUEDES, Neide Cavalcante; MONTEIRO, Adriana Lima. Formação continuada: o conceito e suas implicações na atividade docente. Piauí: UFPI, 2011. (Comunicação oral).

LUNA, Sergio Vasconcelos de. Planejamento de Pesquisa: uma introdução. São Paulo: EDUC, 2000, p.108.

MEDEIROS. Luzia Bernardete. Os sujeitos da EJA e suas marcas. Portal da Educação, 2008. Disponível em: http:www.diaadiaeducacao.pr.gov.br/portals/pde/arquivos/1548-6.pdf. Acesso em: ago. de 2020.

RIBAS, Marciele Stiegler; SOARES, Solange Toldo. Formação de professores para atuar na educação de jovens e adultos: uma reflexão para o desenvolvimento e aperfeiçoamento da prática docente. In: Reunião Anual da ANPEd, 35., 2012, Porto de Galinhas. Anais[...], Porto de Galinhas: Armazém das Letras Gráfica e Editora Ltda, 2012. p. 1-16. Disponível em: http:www.ucs.br/etc/conferencias/index.php/anpedsul/9anpedsul/paper/viewFile/1026/448. Acesso em: set. de 2020.

ROMÃO, José E. Compromisso do educador de jovens e adultos. In: GADOTTI, Moacir; ROMÃO, José E. (Org.). Educação de jovens e adultos: teoria prática e proposta. São Paulo: Cortez, 2006. v. 5.

SACRISTÁN, José Gimeno. Saberes e Incertezas do Currículo. Porto Alegre: Penso, 2013. SEVERINO, Antônio Joaquim. Metodologia do Trabalho Científico. 24. ed. São Paulo: Cortez, 2007.

SOARES, Magda. Letramento: um tema em três gêneros. 2. ed. Belo Horizonte: autêntica, 2003.

SOARES, Solange Toldo. Formação de Professores. São Paulo, Cortez: 2001.

SOUSA, Kesia Costa; CUNHA, Nathan da Silva. Perfil dos alunos da Educação de Jovens e Adultos de Teresina. In: VI Encontro de Pesquisa em Educação da UFPI, 2010, Teresina. Anais [...]. UFPI, 2010. Disponível em: http://leg.ufpi.br/subsiteFiles/ppged/arquivos/files/VI.encontro.2010/GT.19/GT_19_03_2010. pdf. Acesso em: set. de 2020.

SOUZA, Maria Antônia. Educação de Jovens e Adultos. 2 ed. Curitiba: Xibpex, 2011.

TFOUNI, Leda Verdiani. Letramento e Alfabetização. 5.ed. São Paulo: Cortez, 2002. (Coleção Questões da nossa Época; v. 47).

VASCONCELLOS, Celso S. Planejamento: Projeto de Ensino - Aprendizagem e projeto Político Pedagógico. 9 ed. São Paulo: Libertad. 2000. 